\title{
A study on elasto-plastic impact friction
}

\author{
J.P. Nobre ${ }^{\mathrm{a}, *}$, A.M. Dias ${ }^{\mathrm{a}}$, R. Gras ${ }^{\mathrm{b}}$ \\ a Department of Mechanical Engineering, University of Coimbra DEM, Polo II, Pinhal de Marrocos, P-3030 Coimbra, Portugal \\ ${ }^{\mathrm{b}}$ ISMCM-CESTI, Laboratoire de Tribologie, 3, Rue Fernand Hainaut, P-93407 Saint-Ouen, France
}

Received 3 June 1998; received in revised form 29 November 1998; accepted 21 January 1999

\begin{abstract}
A purpose-built pendulum machine was used to study the oblique impact and the behaviour of the surface layers of a normalized low alloy steel subjected to the impact of hard $\alpha$-alumina balls. The effect of relative tangential velocity on impulses, restitution coefficient and impact energy loss, was analysed. The morphology of the impact indentations was characterized and related to the impulses obtained. There was lip formation in the target material with ejection of a small fragile oxidized chip, at a certain critical sliding speed. The impact duration and the impulse ratio have maximum values. These values seem to be related to the critical angle of attack, common in abrasive and erosive ductile processes. The experimental results were compared with some impact models and theories. C) 1999 Elsevier Science S.A. All rights reserved.
\end{abstract}

Keywords: Friction on impact; Oblique impact; Chip formation; Pendulum machine tests

\section{Introduction}

The impact between two components can influence, directly or indirectly, damage to equipment caused by phenomena such as fatigue, wear and fracture. The surface resistance of the materials has a very important economic role. Wear by erosion, for example, is the main cause of failure in industrial equipment like turbomachinery, pneumatic transport, pipelines, offshore structures, etc. The same surface deterioration mechanisms occur in some mechanical surface treatments, like shot-peening, to improve the fatigue resistance of mechanical components. However, the benefit of introducing compressive residual stresses depends on the integrity of the materials' surface.

With the pendulum machine used here we can relate the impulse signals generated on impact to the phenomena occurring during the deformation of the materials' surface layers. Furthermore, after our research on normal impact, we concluded [1] that the equipment used may be a complement or an alternative to the dynamic impact technique (DIT). The DIT technique proposed by Tirupataiah and Sundararajan [2], based on the original theory of Tabor [3] of static and dynamic hardness, basically consists of

\footnotetext{
* Corresponding author. Fax: +351-39-790-701; E-mail joao.nobre@mail.dem.uc.pt
}

projecting hard spheres at a certain velocity onto the test specimens. These authors used it to obtain the dynamic hardness-strain data for copper and iron and characterize their high strain rate plastic flow behaviour $\left(10^{3-4} \mathrm{~s}^{-1}\right)$.

In the present work, the pendulum machine was used to study the oblique impact between a hard sintered alumina ball and a ductile steel target. The effect of relative tangential velocity on impulses, restitution coefficient and impact energy loss was analysed. It was possible to measure the duration of contact and the friction coefficient. The morphology of the impact indentations was characterized and related to the impulses. To analyse and discuss the experimental results we will review some theories and models suggested in this area.

\section{Considerations on solid particle impact}

\subsection{Oblique impact}

Much work has been done in the last 4 decades on the phenomena occurring on impact. Seireg and Weiter [4] studied the friction in the interface between a sphere and two parallel planes. In their experiments, a 1 1/4-in. sphere is suspended between two cylindrical steel pins with parallel flat ends. The normal force is provided by one of the pins which acts as an air piston system. The 
tangential force is applied by the impact of a 1/2-in. sphere. They measured the friction coefficient when sliding starts and concluded that it is higher than when a static force is applied. Maw et al. [5] developed a dynamic analysis of oblique impact between elastic spheres. They used the Hertz contact theory to obtain normal stresses in the contact area. For small sliding velocities, they verified the existence of two different regions on the contact surface. An external annulus where sliding occurs, named the slip region, surrounds a central region where there is no relative tangential velocity, named the stick region. This combined state is called microslip [6]. Other theories have been proposed to explain the complexities involved in collinear or non-collinear impact [6-9]. In the study of the complexities involved in these problems three definitions are given, resulting in three distinct restitution coefficients. A kinematic coefficient, also known as Newton's coefficient (e) (velocity ratio), a kinetic coefficient, also known as Poisson's coefficient $(R)$ (impulse ratio) and an energetic coefficient $(E)$, introduced by Stronge [6], also known as Stronge's coefficient. This coefficient is defined as the square root of the ratio between the elastic strain energy released at the contact point during restitution and the kinetic energy absorbed by internal deformation during compression. According to Stronge [6], the theories based on Newton's impact law or Poisson's impact hypothesis yield errors in energy dissipation if small initial slip stops during collision between eccentric bodies. When small slip is stopped by friction, either the direction of slip reverses or contact points roll without slip. With the theory of Stronge [6] collisions always dissipate energy. Based on the definition of Stronge's coefficient, it can be stated that $0 \leq E^{2} \leq 1$. For a central or collinear impact the relation between these coefficients is given by: $E^{2}=e R$ [7]. Brach [7] discussed the advantages and disadvantages of these coefficients. When used in impact problems, the kinematic (or kinetic) coefficient leads to a linear system of equations. Stronge's energetic coefficient allows a more consistent theory of impact, but its use in impact problems leads to a non-linear system of equations. Brach [7] proposed a classical impact theory to explain the planar eccentric impact. He confirmed that the solutions for the planar collision problem can be unrealistic because of the improper treatment of the tangential impulse (effects of indentation, viscous friction and Coulomb (dry) friction). Stronge [8] also introduced a lumped parameter model of contact between colliding bodies to obtain the tangential force and energy dissipated by friction during oblique impact of rough compliant bodies. He used Coulomb's law of friction and the energetic restitution coefficient. His analysis distinguishes between angles of incidence $\left(0^{\circ}\right.$ at normal impact) where the contact point initially sticks, slides before sticking or slides throughout the contact period. This model seems to be of use in dealing with inelastic collisions where the contact region has no negligible tangential compliance. However, more problems arise for higher impact speeds, when the impact energy is large enough to develop significant permanent indentation [8].

\subsection{Friction on impact}

The friction coefficient on impact is of fundamental importance to wear by solid particle impact because it defines the fatigue strength and the microcutting of the body being worn $[10,11]$. On impact, based on Coulomb's law, some authors define a friction coefficient by $[10,11]$ :

$\mu=\frac{\int T \mathrm{~d} t}{\int N \mathrm{~d} t}=\frac{P_{\mathrm{t}}}{P_{\mathrm{n}}}$

where the $T$ and $N$ are the tangential and normal impact force generated on impact. However, this is only true in glancing impact, i.e., when sliding does not stop during contact [12]. Generally, in the case of the impact between two bodies, where, for a particular referential, the angular and linear velocities of the bodies, before and after the impact, are known, the friction coefficient can be written as follows $[10,11]$ :

$\mu=\frac{v_{\mathrm{i}} \cos \theta_{\mathrm{i}}-v_{\mathrm{f}} \cos \theta_{\mathrm{f}}}{v_{\mathrm{i}} \sin \theta_{\mathrm{i}}+v_{\mathrm{f}} \sin \theta_{\mathrm{f}}}$

where the subscript $i$ refers to the initial values and $f$ to the final values (normal impact occurs at $\theta_{\mathrm{i}}=90^{\circ}$ ). Ratner and Styller [10] used three methods to measure the friction coefficient under impact: a tensiometric method (via Eq. (1)); high speed filming and photography with a stroboscope; and a special tribometer (via Eq. (2)). They studied the character of the $\mu=f\left(\theta_{\mathrm{i}}\right)$ curves and determined that the friction coefficient on impact depends substantially on the attack angle and that these curves may be divided in two regions: small and medium angles (up to $40-60^{\circ}$ ) and large angles (greater than $40-60^{\circ}$ ). In the range of small and medium values of $\theta_{\mathrm{i}}$ the impact friction decreases with an increase of the attack angle coefficient for elastomers and increases with the increase of the attack angle for plastics. For large values of $\theta_{\mathrm{i}}$ the friction coefficient of all materials decreases and approaches zero on normal impact. They concluded that the fundamental differences between friction and wear under impact and wear under sliding are the pressure (i.e., the load responsible for friction) and the friction coefficient. After qualitative interpretation of the results, they used the dynamic equivalents of both factors (function of the particle velocity and attack angle) to determine specific quantitative characteristics of wear under impact based on the already established features of wear under sliding contact [10,11]. Brach [12] contested this approach and considered that a distinction between the impulse ratio and the friction coefficient is necessary for a proper interpretation of impact data. Brach [12] assumes that the classic impact theory, based on 
Newton's laws, can successfully be used to describe impact phenomenon. Supposing that there is a unique solution for the final velocity components of impact particles, then we can define two constants (the kinematic restitution coefficient $0 \leq e \leq 1$ and the impulse ratio (Eq. (1))) which allow a complete solution for the problem [12]. Brach [7] points out that this approach foresees the study of arbitrary tangential processes (not just dry friction) and the ability to express the solution of the impact problem and the corresponding energy loss in terms of the initial velocities and the parameters $e$ and $\mu$. In his impact model, Brach [7,12] defined a limiting value for impulse ratio $\mu$. Under any condition (whether the friction coefficient is a constant or not and even when the tangential force is not due to sliding friction) the value of the tangential impulse can never exceed $\mu_{\mathrm{c}} P_{\mathrm{n}}$. For the impact of a rigid body (a body with significant mass moment of inertia) against a plane surface the limiting value of the impulse ratio corresponds to the situation where sliding stops at separation and is given by $[7,12]$ :

$\mu_{\mathrm{c}}=\frac{1}{1+\lambda} \frac{r}{(1+e)}$ with $\lambda=\frac{R^{2}}{k^{2}}$

where $r=v_{\mathrm{t}} / v_{\mathrm{n}}$, not considering the angular velocity of the rigid body, $v_{\mathrm{t}}$ and $v_{\mathrm{n}}$ are, respectively, the initial tangential and normal impact velocities of the mass centre; $e=-v_{\mathrm{fn}} / v_{\text {in }}$ is the kinematic restitution coefficient, $v_{\mathrm{fn}}$ and $v_{\text {in }}$ are the final and initial normal velocity components at the contact point, respectively; $R$ is the particle radius and $k$ is the radius of gyration $(\lambda=5 / 2$ for a spherical rigid shape and $\lambda=0$ for a point mass). Other models use critical values that can be related to Eq. (3). For example, we can deduce this value from the lumped parameter impact model by Stronge [8]. In this model, for a perfectly rigid particle, 'gross slip' begins when:

$\frac{v_{\mathrm{t}}}{v_{\mathrm{n}}}>\frac{7}{2} \mu(1+e)$

where $v_{\mathrm{t}}$ and $v_{\mathrm{n}}$ are the tangential and normal initial components of impact velocity; $\mu$ is the Coulomb's friction coefficient and $e$ is the Stronge's energetic restitution coefficient. The critical impact angles used in some solid particle erosion models [13-15] can also be related with Eq. (3).

In the impact model by Brach [12], the critical value given by Eq. (3) is the value of the impulse ratio that maximizes kinetic energy loss. This is a useful concept for engineering applications. Brach [12] calculated a non-dimensional form for energy loss on impact (ratio between energy loss and initial kinetic energy) given by:

$E_{\mathrm{loss}}^{*}=\frac{1-e^{2}}{1+r^{2}}+\frac{r^{2}}{1+r^{2}} \frac{1}{1+\lambda} \frac{\mu}{\mu_{\mathrm{c}}}\left(2-\frac{\mu}{\mu_{\mathrm{c}}}\right)$.

The two terms of Eq. (5) represent the energy lost due to the normal and tangential effects, respectively. Note that, if the initial angular velocity is null, $r=1 / \tan \theta$, where $\theta$ is the impact angle (equal to $90^{\circ}$ for normal impact).

In the model of Stronge [8], during inelastic collisions, there is always irreversible internal deformation that dissipates a part of the initial kinetic energy. For collinear collisions, the part of the kinetic energy that is dissipated by irreversible deformation is proportional to $\left(1-e^{2}\right)$. Friction dissipates energy only during periods of slip. Stronge [8] deduced equations to calculate energy loss due to tangential effects. However, only the normal compliant element is irreversible and, consequently, energy losses due to internal hysteresis and those due to friction remain decoupled. If the impact energy is large enough to develop significant permanent indentation (uncontained plastic deformation), the inelastic internal deformation depends on both normal and tangential components of contact force and, in these cases, the sources of dissipation are no longer assignable to separate components of force, nor representable by coefficients which are independent of the impact angle [8].

\subsection{Behaviour of ductile material targets}

The deformation of ductile target materials subjected to impact by hard projectiles, in the range of low and medium impact velocities $(<500 \mathrm{~m} / \mathrm{s})$, common in practical engineering, is predominantly plastic and the elastic and hydrodynamic components can be disregarded [2,9]. However, plastic deformation occurs at high strain rates $\left(10^{3-4} \mathrm{~s}^{-1}\right)$ and this is a new obstacle in the determination of the energy absorbed during impact $[1,16,17]$. Sundararajan [9] verified that the energy absorbed by the target material during each impact is a very strong function of both impact velocity and impact angle. He used three specifically developed models for the oblique impact of a sphere onto a plane target: two analytical $[7,10]$ and one numerical [9]. He concluded that the numerical model gave better results. The model, similar to the one introduced by Hutchings et al. [18,19], and Rickerby and Macmillan [20], was based on the hypothesis that the force resistant to indentation can be represented by a constant indentation pressure (dynamic hardness) and, related to it by Coulomb's law, a small friction force. It allowed the description of the variation of crater volume and energy dissipated on impact with the impact angle and impact velocity. However, this model underestimates the observed rebound angles. The cause is attributed to the process of lip formation in the crater front zone. Moreover, since the model disregards the elastic recovery, it is not possible to predict the rebound of the spheres in normal impact cases. Sriram and Kosel [21] have improved the model by introducing the effect of the elastic energy stored on impact and the rotational energy of the sphere. 
An important application of the theories and models referred above is the case of erosion wear by solid particle impact. Finnie [13] proposed one of the first models on erosion wear. This simple model, based on metal cutting processes, allowed the knowledge of the variation of the erosion rate (mass of removed material by unit mass of projectiles) with the impact angle. For ductile materials and for low impact angles, the model works very well. The equations of Finnie [13] can be deduced from the classical impact theory of Brach [12], if we consider $e=1$ and, for high impact angles, $\mu=\mu_{\mathrm{c}}$. Bitter [14,15] first split the wear mechanisms in two: deformation wear and cutting wear. In this model, the wear rate is the sum of these two contributions. The model of Bitter [14,15] is based on a material energetic criterion. Both authors showed the contradictory behaviour of ductile and fragile materials [22]. Neilson and Gilchrist [23] proposed a simplified model based on the model of Bitter [14,15].

All works show the existence of a critical attack angle in the ductile erosion cases. Most of the models that have been proposed for solid particle erosion have had great difficulty in predicting the effect of impact velocity [2427]. Other authors, like Hutchings [25] and Kragelsky [11] have proposed fatigue models to explain erosive wear. The model of Ratner and Styller [10] was developed to explain the erosion wear found in polymeric materials. However, these models do not explain other phenomena that occur in erosion on ductile materials' surfaces, namely, lip formation.

By using scanning electronic micrographies (SEM) and TEM techniques, Ives and Ruff [28] studied the topography and the subsuperficial damage that occurs in stainless steel (310) surfaces caused by the impact of erosive particles. They used two types of particles: sharp alumina $\left(\mathrm{Al}_{2} \mathrm{O}_{3}\right)$ particles and spherical glass particles at $59 \mathrm{~m} / \mathrm{s}$ and two impact angles $\left(25\right.$ and $90^{\circ}$ ). In these conditions they did not observe any material removal (detached lips), thus confirming the existence of a critical velocity observed by Hutchings and Winter [29]. They also compared their findings with those obtained in quasi-static hardness tests and concluded that there were no substantial differences. The density and arrangement of the dislocations are identical in all cases and they confirmed a zone of high dislocations density around the craters. Hutchings [25] compared the subsurface layers of ductile steels subjected to impact and quasi-static tests. In quasi-static indentation, the lines defining the orientation of the perlitic microstructure present an inflexion, approximately in the zone where the maximum shear stress occurs (predicted by the Hertz theory of contact-see Ref. [17]). However, in impact indentations, those lines tend to compress in the direction of the indentation contour, extruding the material in the contour. Sundararajan and Shewmon [26] proposed a new model for the erosion of metals at normal impact, designated localized strain model. Based on the work of Sundararajan [27], the model postulates that any volume ele- ment of the target is lost by localized lip formation when a critical value of strain is exceeded in its interior.

According to the theory of Sundararajan [27] the lip is formed by localized plastic deformation in the near surface of the target material. Single particle normal impact experiments in some metals (TD-Ni and aluminium alloy 7075-T6) showed that localized deformation, i.e., lip formation, occurs for all impact velocities $(>30 \mathrm{~m} / \mathrm{s}$ ), while in solid solutions like bronze or in stainless steel (301 and $304)$ this phenomenon only occurs when the impact velocity reaches a critical value between 150 and $200 \mathrm{~m} / \mathrm{s}$. Besides, while copper exhibits lip formation in all impact velocities used (although it does not occur in quasi-static tests), nickel does not show this behaviour in the range of impact velocities used $(<180 \mathrm{~m} / \mathrm{s})$ [27]. Sundararajan [27] formulated equations to obtain values for the critical strain and velocity corresponding to the beginning of the lip formation phenomenon in normal impact, independently of the strain ratio (dynamic or quasi-static tests). Sundararajan [30] also studied the nature and size of the plastic zone beneath the eroded surface and correlated the plastic zone size with the erosion rate.

The importance of the deformation effects and plastic flow behaviour on the erosion of ductile materials has been studied since the 1970s. Hutchings and Winter [29] accomplished one of the first studies on mechanical removal processes of ductile erosion and observed that these processes are similar to those occurring in abrasive wear. Rabinowicz [31] also considered that erosion by impingement of abrasive particles against a solid surface is a form of abrasive wear and can be described by the well known standard abrasive wear equation proposed by this author, with suitable modifications. Hutchings and Winter [29] considered two mechanisms in material removal processes: plastic deformation and microcutting. On oblique impact of $3 \mathrm{~mm}$ steel balls and metal targets at velocities up to $250 \mathrm{~m} / \mathrm{s}$, they observed the phenomenon of lip formation. The lip is formed at the exit end of the crater by the shearing of the surface layers. Above a critical velocity, characteristic of the particular metal, this lip is detached from the surface by the propagation of ruptures at the base of the lip. This process occurs more easily in cold worked copper than in annealed copper [29].

During simulation of abrasive processes, Sedriks and Mulhearn [32] demonstrated the existence of a critical attack angle. Depending on the rake angle (ploughing of target material or cutting with a continuous chip formation), they observed a rapid variation in the value of the grooves' areas. Many researchers [30,33] have noted behaviour differences between pure metals and steels when subjected to abrasive wear. Huard and Fiset [33] studied the influence of the materials' microstructure on critical attack angle. They mentioned that the same critical attack angles, observed with pure metals, should support the linearity between the abrasion wear resistance and their hardness. However, in the case of steels, the critical attack 
angle decreases as its hardness increases. Furthermore, the annealed steels showed the same behaviour as pure metals where 'ploughing' is predominant. However, these steels are more sensitive to cutting wear in quenched state. This phenomenon does not seem to occur in the case of pure metals. Huard and Fiset [33] concluded that the materials' behaviour to plastic deformation has an important role in the apparent friction coefficient. In fact, they observed that the apparent friction coefficient varied with the abrasion mechanism and the attack angle of the abrasive particles. Their tests on eutectoid steel 1080 showed a reduction in the critical attack angle with the increase of its hardness. They concluded that the strain hardening coefficient is an important parameter in the characterization of these processes, unlike ductility. Challen et al. [34] used a slip line model to explain the effect of a hard abrasive particle ploughing the surface of a ductile material with a high attack angle and explain the theories of metal machining for low attack angles. They showed that the transition of the wave model (ploughing) to cutting model, given by the value of a critical attack angle, depends on the interfacial friction coefficient (abrasive particle/surface material or abrasive particle/chip). These authors showed that the critical attack angle (smallest angle of abrasive particle that allows chip formation) should increase with the increase in work hardening.

\section{Materials, experimental equipment and procedure}

We studied the behaviour of a ductile low alloy steel (steel AFNOR 25CD4-normalized) subjected to the oblique impact of sintered $\alpha$-alumina balls $(11 \mathrm{~mm} \pm 0.5$ $\mathrm{mm}$ mean diameter, hardness of $2100 \mathrm{HV}$ and elastic constants: $E=300 \mathrm{GPa}$ (Young's modulus) and $\nu=0.22$ (Poisson's coefficient)). Table 1 summarizes some of the mechanical properties of the steel used, determined at room temperature. For the elastic constants we used the hand book values.

The impact test machine consists of a pendulum hammer equipped with a multiaxial piezoelectric transducer rigidly linked to it. This transducer uses an oscilloscope with memory to measure impact impulses after signal amplification. A pre-tension of $2.5 \mathrm{kN}$ is applied to obtain good linearity $(<1 \%)$. Under these conditions it is possi-

Table 1

Mechanical properties of steel AFNOR 25CD4 ${ }^{\text {a }}$ (according to standard ASTM E 646)

\begin{tabular}{|c|c|c|c|c|c|}
\hline $\begin{array}{l}\text { Yield stress, } \\
\sigma_{\mathrm{Y}}(0.2 \%) \\
(\mathrm{MPa})\end{array}$ & $\begin{array}{l}\text { Strength } \\
\text { stress, } \sigma_{\mathrm{R}} \\
(\mathrm{MPa})\end{array}$ & $\begin{array}{l}\text { Ultimate } \\
\text { stress, } \sigma_{\mathrm{UT}} \\
(\mathrm{MPa})\end{array}$ & $\begin{array}{l}\text { Strain at } \\
\sigma_{\mathrm{R}}, \varepsilon_{\mathrm{R}} \\
(\%)\end{array}$ & $\begin{array}{l}\text { Ultimate } \\
\text { strain, } \varepsilon_{\mathrm{f}} \\
(\%)\end{array}$ & $\begin{array}{l}\text { Strain } \\
\text { hardening } \\
\text { exponent, } n\end{array}$ \\
\hline$=30$ & $660 \pm 14$ & $520 \pm 15$ & $1 \pm 0.5$ & $19 \pm 0.8$ & $0.17 \pm 0.02$ \\
\hline
\end{tabular}

${ }^{a}$ Normalized at $860-900^{\circ} \mathrm{C}$. Approximate chemical composition: $0.25 \%$ C, $0.25 \% \mathrm{Si}, 0.65 \% \mathrm{Mn}, 1.05 \% \mathrm{Cr}$, and $0.20 \% \mathrm{Mo}$. ble to measure compressive forces up to $5 \mathrm{kN}$ and shear forces up to $2 \mathrm{kN}$. The pendulum is made to strike a cylindrical specimen, which can be given a rotational movement by a $736-\mathrm{W}$ electrical motor. The linear velocity of the pendulum at impact can vary between 0 and 2.3 $\mathrm{m} / \mathrm{s}$ and the linear velocity of cylindrical track between 0 and $30 \mathrm{~m} / \mathrm{s}$. The velocity of the pendulum and cylindrical track, before and after impact, can be registered photoelectrically. An inertia flywheel was used to stabilize the rotational velocity of the shaft machine. The dynamic balance of the shaft was performed at $650 \mathrm{rot} / \mathrm{min}$. The cylindrical steel specimens used here have a diameter of about $100 \mathrm{~mm}$. Fig. 1 shows the machine and the measuring system used. Some characteristics of the pendulum machine are [35,36]:

-pendulum mass: $4.922 \mathrm{~kg}$;

-length of percussion: $0.345 \mathrm{~m}$;

-moment of inertia relative to pendulum rotation axis:

$0.408 \mathrm{~kg} \cdot \mathrm{m}^{2}$;

-moment of inertia relative to cylinder rotation axis:

$0.05 \mathrm{~kg} \cdot \mathrm{m}^{2}$;

-pendulum impact velocity: 0.32 to $2.3 \mathrm{~m} / \mathrm{s}$;

-pendulum kinetic energy: 0.18 to $9.6 \mathrm{~J}$;

-cylinder tangential velocity: 0.2 to $30 \mathrm{~m} / \mathrm{s}$.

The compound pendulum was designed and built to obtain a length of percussion $(l)$, defined by the distance between the impact point and the rotational axis, which corresponds to the length of the synchronous pendulum associated with it. To minimize vibration effects, the length of the pendulum arm $(0.267 \mathrm{~m})$ and the pendulum mass distribution were obtained considering two conditions: one related with the natural frequency of the $\operatorname{arm}(<0.295 \mathrm{~m})$ and the characteristics of the measurement system used; another related with the percussion reactions on the bearings. In our system, these reactions can be disregarded. The centre of percussion is close to impact point, above $2.5 \mathrm{~mm}$ in the symmetrical axis of the pendulum. To fulfil these conditions the resultant impact force must be normal to the plane defined by the same axis and the rotation axis of the pendulum. Consequently, preliminary tests must be done to measure the mean friction angle $\beta$, for each impact condition (see Fig. 8 and Ref. [35]).

The pendulum machine provides information on the history of the impact. It is thus possible to relate the phenomena occurring during the deformation of the materials surface layers with the signals of the impact impulses, and study the mechanisms involved in the processes of material removal, namely chip formation. We studied the behaviour of impulses, when relative tangential velocity increases from 0.2 to $16 \mathrm{~m} / \mathrm{s}$. We used two different launch angles 10 and $20^{\circ}$, corresponding to two impact kinetic energies of about 0.18 and $0.7 \mathrm{~J}$, respectively. The corresponding pendulum velocity remained nearly constant, equal to 0.32 and $0.64 \mathrm{~m} / \mathrm{s}$. The surfaces of the specimens were rectified after machining. For each impact test the projectiles were changed and the tracks cleaned 


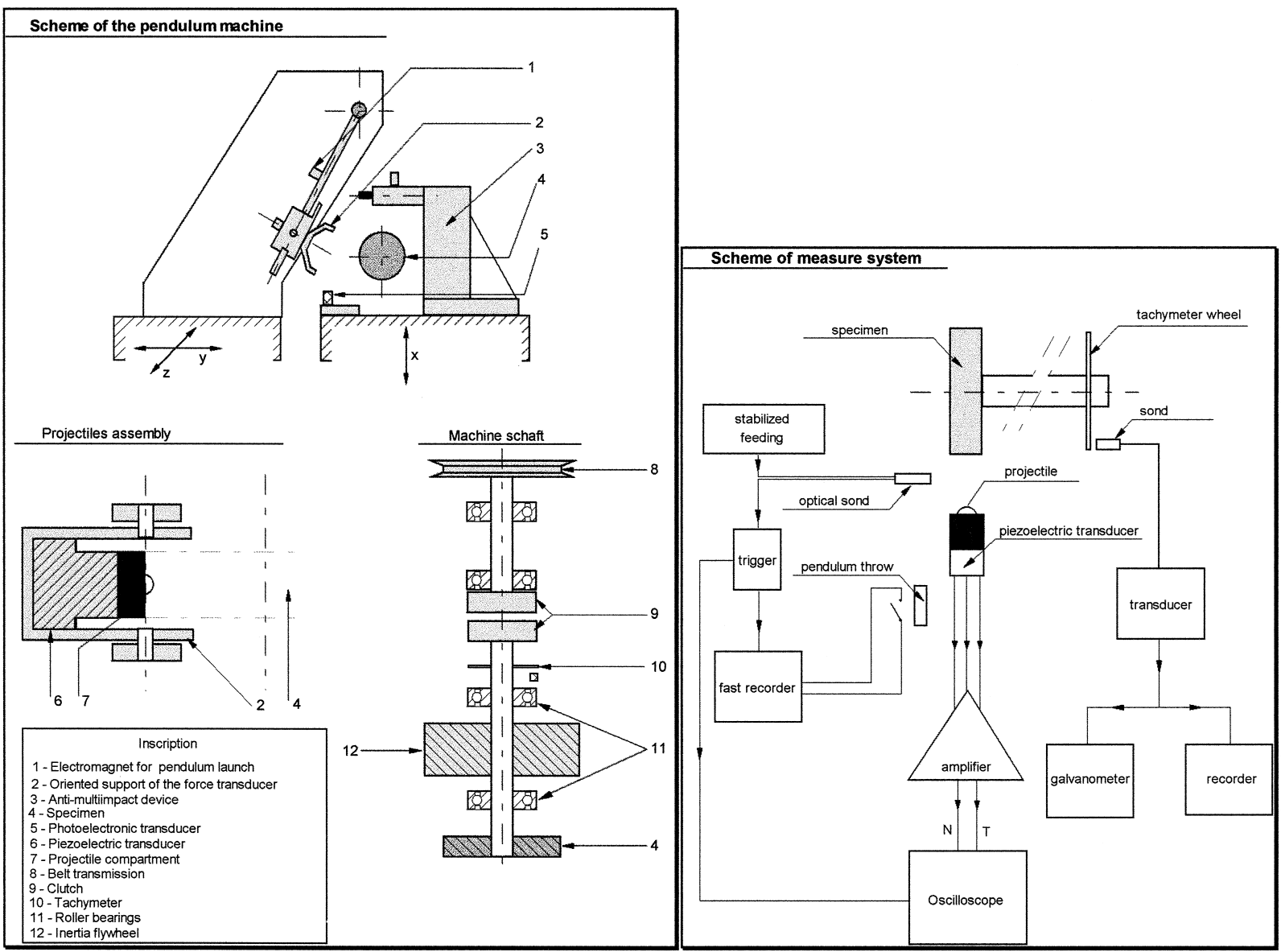

Fig. 1. Description of the impact machine.

with tetrachloroethylene and ether. The tests were carried out at ambient temperature and without lubrication (dry friction).

\section{Experimental results and discussion}

\subsection{Indentation morphology}

In a previous work [1] on normal impact, we found that there was no lip formation, within the range of the impact energy used (elasto-plastic impact). The impact indentation was identical to the quasi-static one. The average dynamic pressure does not seem to be constant and is higher than the value obtained in quasi-static indentation. In the present work, the effect of relative tangential velocity on impulses, restitution coefficient and impact energy loss was analysed. The morphology of the impact indentations is now characterized and related to the impulses.

The target surface showed impact marks in all tests (the length of indentation is proportional to tangential velocity) and the projectile showed traces of material transfer. At low tangential velocities the indentation showed lateral and frontal lips. For tangential velocities lower than $1 \mathrm{~m} / \mathrm{s}$, the bottom of the indentation on the steel tracks showed two distinct zones: a wrinkled inner zone and a grooved outer zone, clearly defined by a brilliant circular annulus (see Fig. 3a)). These two regions are called stick and slip, respectively, and this combined state is termed microslip [8]. For the lowest tangential velocities the sliding stops during the impact charge phase. The ratio between the tangential and normal impulses increases considerably in this region. For higher velocities $(<2 \mathrm{~m} / \mathrm{s})$ the craters still present two distinct zones: an initial brilliant grooved zone (sliding) and a final, quite wrinkled zone (sticking). During this period, the formation of a lip in the frontal zone of the indentations was confirmed. The process is essentially based on the plastic deformation of the material's superficial layers. The material is subjected to ploughing during the initial phase of impact and some material is accumulated in the final zones of the craters. The sliding is interrupted in the impact rebound phase. Optical microscopy shows that there is material transfer from the tracks to the alumina projectiles which, associated with high roughness in the final zones of the craters, enables us to consider that adhesive phenomena are quite important in this phase. The frontal zones outside the craters exhibit 'wavy' zones, which can be related with the 
appearance of adiabatic shear bands [18,28]. The impulse ratio increases rapidly.

For tangential velocities near $2 \mathrm{~m} / \mathrm{s}$, a large accumulation of material can be seen in the frontal zone of the indentations. The bottom of the craters presents alternate zones, irregularly grooved and wrinkled. The beginning of the crater presents grooves, followed by a wrinkled transition zone, which delimits a grooved central zone. The final zone of the crater is quite wrinkled and using a microscope we can see small circles indicating that material was torn out. There are peaks in the signal of the tangential impulse. The different zones were measured using microscopy and, based on the tracks' rotation velocity, it was possible to associate the peaks of the signal with these zones. There is a relation between the signal and the appearance of irregularities at the bottom of the craters. The wavy zone in the external frontal area of the craters becomes more compact and spreads to the lateral zones of the indentations. When a certain critical velocity is reached, as Hutchings and Winter [29] observed, the chip formed by deformation and cut of the material is ejected from the surface of the test specimens. For velocities near the critical tangential velocity, the chip formed remains over the frontal zone of indentation. SEM of the craters show two symmetrical fractures in the frontal zone of the crater, which will be responsible for the separation of the chip (see Fig. 2). The final zone of the craters presents longitudinal grooves and is not wrinkled. Fig. 2 shows the appearance of different zones at the bottom of the indentation. A very small wrinkled zone, followed by a grooved zone, followed by a wrinkled zone and so on. These zones, at the bottom of the craters, seem to be associated with the extraneous frequency of about $1.6-2 \mathrm{kHz}$ in the signal of the impulses. It is important to notice the morphology of the chip's surface in the micrography in Fig. 2b). The high roughness of the chip's surface must be related to the adhesion that occurs in the chip/projectile interface. The impulse ratio reaches a maximum. For velocities between 2 and $3 \mathrm{~m} / \mathrm{s}$ a fragile chip is ejected from the tracks, presenting a bluish colour, evidence of strong oxidation. The oxides that are formed indicate that the local temperatures attained must have been very high, to activate the chemical reactions involved. The craters present more regular contours and the 'wavy' bands, appearing in the frontal zone, shift towards the lateral walls, where accumulation of material is verified. These results seem to indicate that the adhesive phenomena are important to the formation and ejection of the chips.

Over $3 \mathrm{~m} / \mathrm{s}$ the chip sticks to the sphere, getting loose easily. The bottom of the craters presents longitudinal grooves, but small zones of transition between the grooved zones were observed. These are related to the impulses signal peaks. The grooves result from the abrasion caused by the asperities of the alumina or, for high sliding velocities, by abrasive particles (debris) formed at the beginning of impact. It was determined that the length of the craters
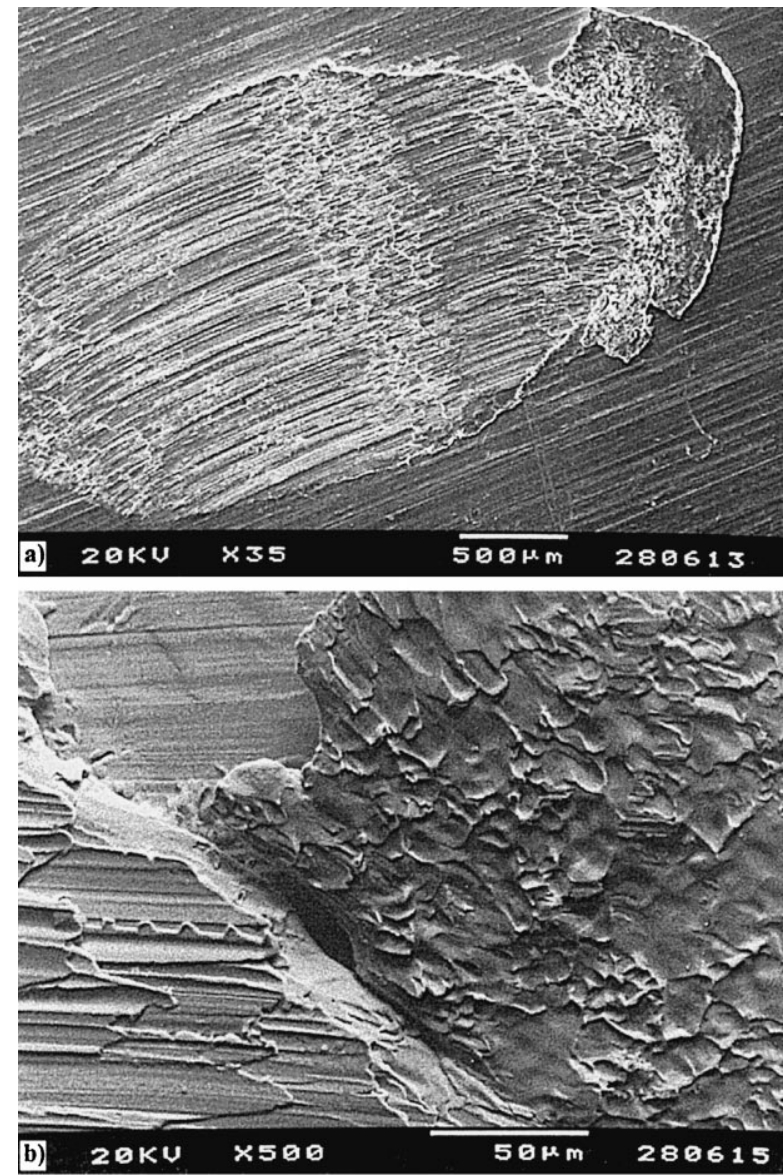

Fig. 2. (a) SEM micrography of the indentation corresponding to velocities close to the critical tangential velocity (chip on the track). (b) Separation zone between the indentation and the chip $\left(V_{\mathrm{t}} \sim 2 \mathrm{~m} / \mathrm{s}\right.$ and $\left.E_{\mathrm{c}}=0.7 \mathrm{~J}\right)$.

increases in proportion to the sliding velocity and is nearly independent of the impact velocity. Furthermore, the width of indentations seems to present a maximum value when the critical velocity is reached. Their contours become more regular. There are no frontal bands. These become more visible in the outer zone of the lateral outlines. At higher velocities, abrasion grooves are still seen at the bottom of the indentations and small fragments of material are observed in their lateral zones. At velocities over about $12 \mathrm{~m} / \mathrm{s}$, the chip sticks strongly to the projectile, breaking into small fragments when we try to remove it. An identical phenomenon, related to the alternate zones at the bottom of the craters, was observed by Sedriks and Mulhearn [32] during tests on the simulation of the abrasive process. It should be noted that the extraneous frequency $(1.6-2 \mathrm{kHz})$, related to the distinct zones observed at the bottom of the craters, is identical to the frequencies found in the process of chip formation, typical in metal machining. However, according to the lumped parameter impact model of Stronge [8], this is also a natural frequency, corresponding to an impact at $10^{-3} \mathrm{~s}$ for the compression phase time observed in our tests. Fig. 3 summarizes the evolution of the indentations with tangential velocity. 

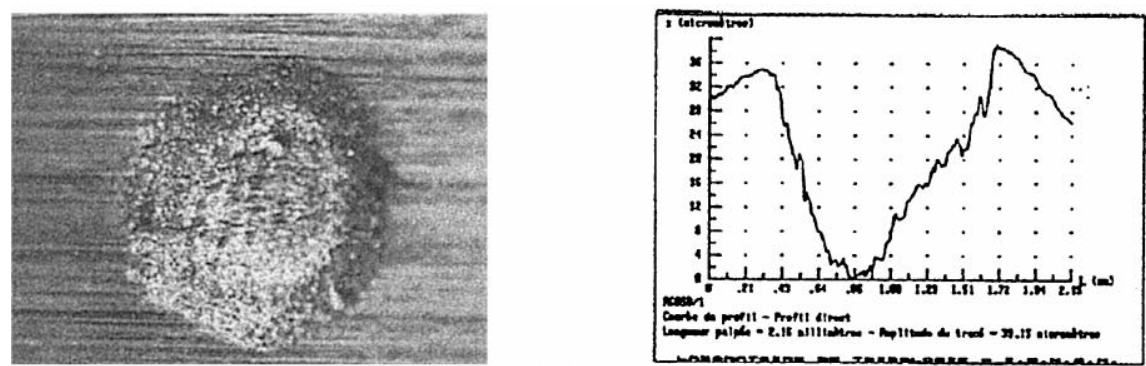

a) $E c=0.71 \mathrm{~J} ; V<1 \mathrm{~m} / \mathrm{s}$
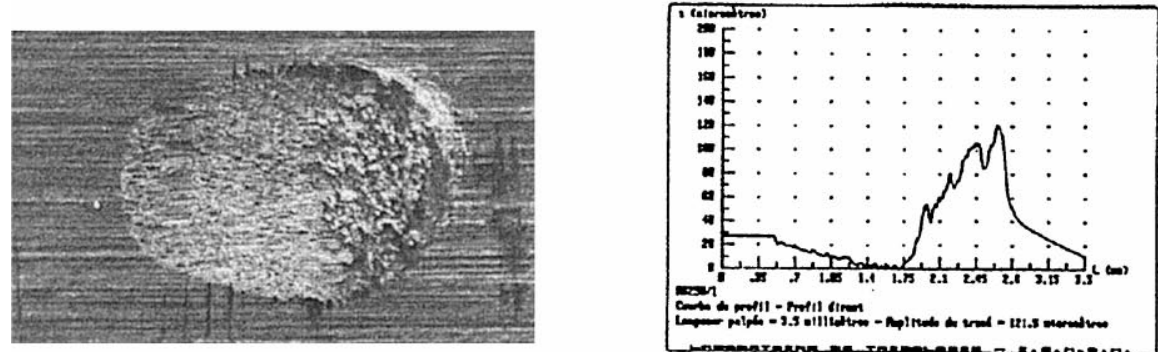

b) $E C=0.71 \mathrm{~J} ; \mathrm{V}<2 \mathrm{~m} / \mathrm{s}$
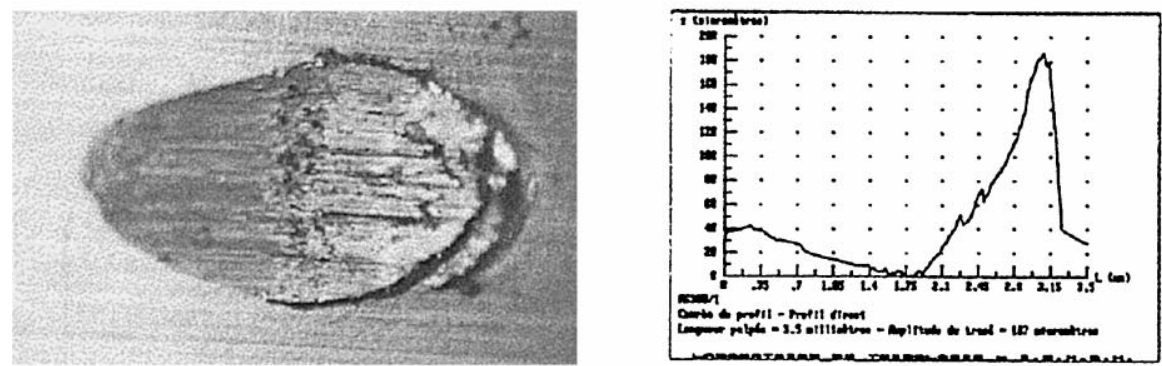

c) $E c=0.71 \mathrm{~J} ; V \approx 2 \mathrm{~m} / \mathrm{s}$
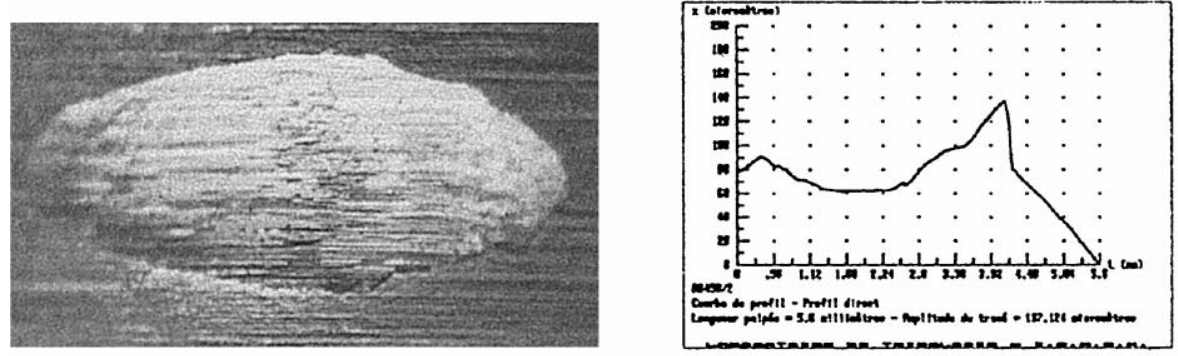

d) $\mathrm{Ec}=0.71 \mathrm{~J} ; \mathrm{V}>2.5 \mathrm{~m} / \mathrm{s}$

Fig. 3. Optical micrographies and longitudinal profiles of the indentions showing the process of lip formation and ejection of the chips.

\subsection{Time of contact, forces and restitution coefficient}

The impulses' signal clearly shows that the impact has two phases: a compression or charge phase and a rebound or discharge phase. In normal impact tests, the impact charge phase is always shorter than the discharge phase and the difference becomes greater as impact velocity increases [1]. In oblique impact, the duration of impact increases rapidly and reaches a critical value. In fact, when we have a finite tangential velocity, in the microslip zone, the duration of the rebound phase and the duration of contact increases rapidly. The variation in the duration of the rebound phase may be explained by the effect of adhesive forces in the contact interface. Fig. 4 shows the variation of the total duration of contact with the tangential velocity for two launch angles $\left(10\right.$ and $20^{\circ}$ ), corresponding 


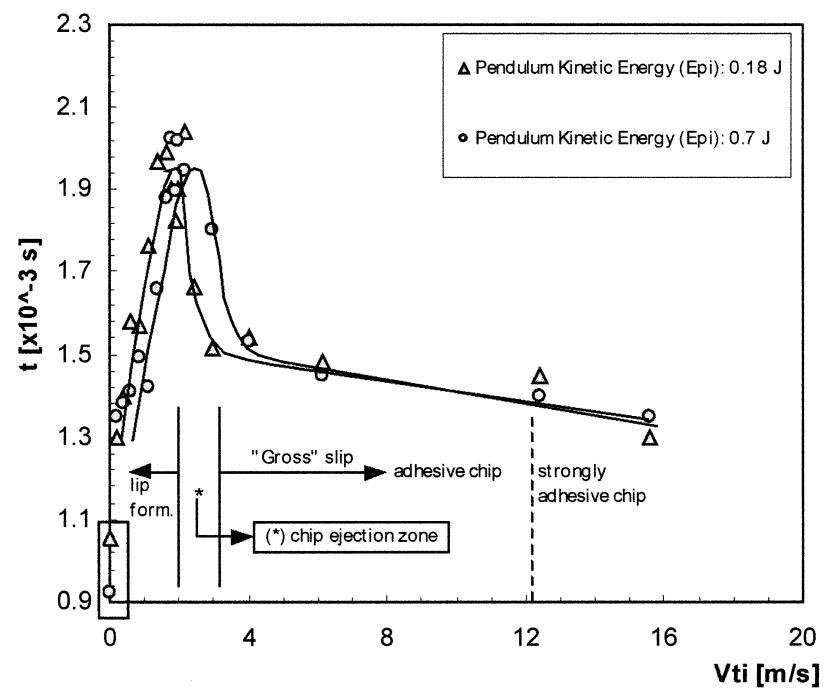

Fig. 4. Impact duration vs. tangential velocity.

to pendulum kinetic energies at the moment of impact of about 0.18 and $0.7 \mathrm{~J}$, respectively. Note the sudden increase of the contact duration when the tangential velocity ceases to be null. The points corresponding to the case of normal impact $\left(V_{\mathrm{t}}=0 \mathrm{~m} / \mathrm{s}\right)$ are marked in Fig. 4 .

It can be observed that the total contact duration increases rapidly with tangential velocity, reaching a critical value from which an abrupt decrease of the contact duration is seen. It was verified that this maximum value is related to the phenomena of formation and ejection of the chips, as described in the Section 4.1. For high sliding velocities the contact duration slowly decreases to values identical to those obtained in the case of normal impact $\left(V_{\mathrm{t}}=0 \mathrm{~m} / \mathrm{s}\right)$. This behaviour is mainly due to the duration of the rebound phase. Analysis of the impulses shows that, when the tangential velocity increases, the duration of the rebound phase increases considerably. The contact duration increases abruptly. Above the critical velocity, after the chips are ejected, there is a continuous decrease of the rebound phase as the tangential velocity increases.

Fig. 5 shows the variation of the maximum normal and tangential forces with tangential velocity, which correspond to $0.7 \mathrm{~J}$ of pendulum impact energy. It can be seen that the curve of the maximum normal force presents a minimum. It was observed that this behaviour of the normal force curve tends to be more pronounced as the impact velocity increases. The tangential force increases rapidly with the increase of the tangential velocity until there is chip ejection. At this point there is a strong inflexion in the measured tangential force. The lumped parameter impact model of Stronge [8] was successfully used to describe the behaviour of maximum normal and tangential forces with tangential velocity (see Section 5.2).

Using Coulomb's friction law, we can determine a friction coefficient defined by the ratio of the maximum tangential force and the maximum normal force. This is

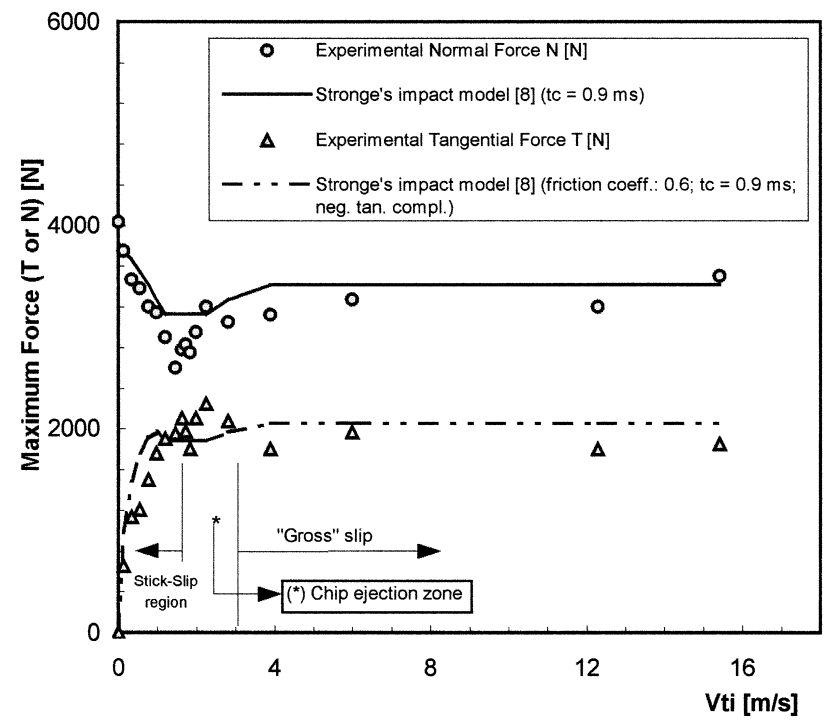

Fig. 5. Maximum normal and tangential forces vs. tangential velocity $\left(E_{\text {ip }}=0.7 \mathrm{~J}\right)$.

approximately true because, as Lewis and Rogers [37] demonstrated, the friction coefficient rises to a 'plateau' value during contact and then declines to zero as contact is lost. This value seems to be independent of impact velocity and a bilinear function of the impact angle [37]. Fig. 6 shows the evolution of the friction coefficient with relative tangential velocity. We can see that, for low tangential impact velocities, it increases rapidly with the increase of tangential velocity, reaches a maximum value and then decreases slowly.

It is visible that the impact can be divided into two parts. The first one corresponds to the range of low tangential velocities (high incidence angles) in which the process is characterized by a continuous rapid increase of the impulse ratio. This ratio seems to have a limiting value

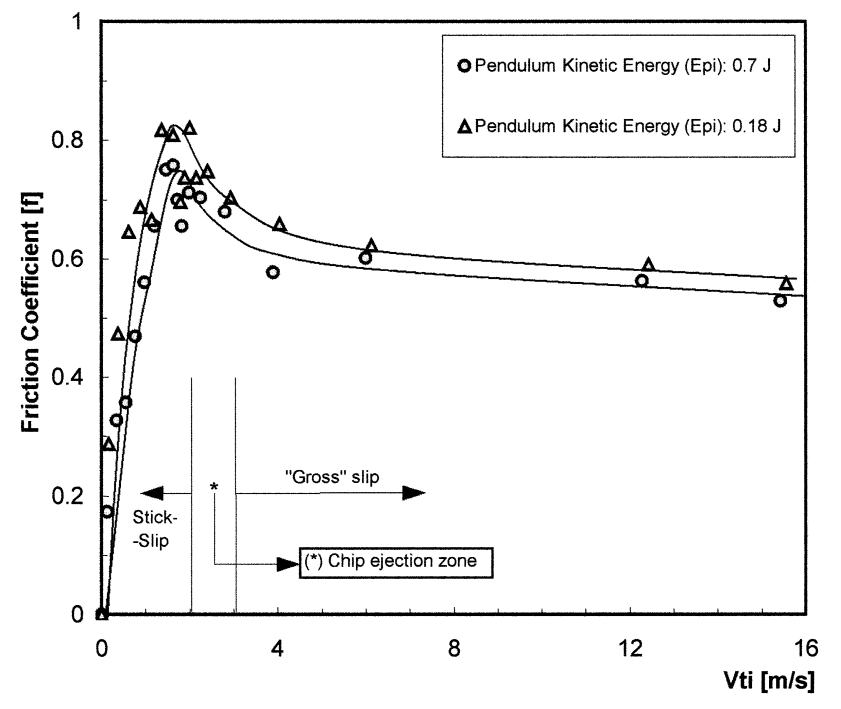

Fig. 6. Friction coefficient vs. initial tangential velocity. 


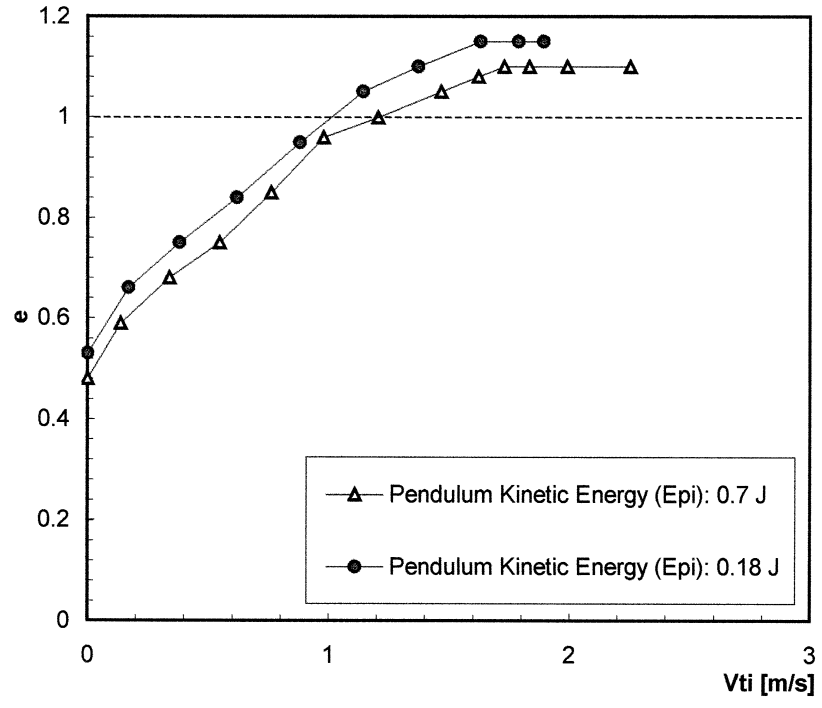

Fig. 7. Kinematic restitution coefficient vs. initial tangential velocity.

related to the value deduced by Brach [12] (see Section 5.2). Brach's critical impulse ratio must have some physical signification. In this region, sliding probably stops during contact time. For the lowest tangential impact velocity, the morphology of indentations shows microslip (stick-slip region) phenomena. For higher tangential velocities the adhesion phenomena should be activated. When a critical tangential velocity is reached, corresponding to an incidence impact angle between 10 and $20^{\circ}$, a fragile oxidized chip is ejected from test targets. Some ejected chips have a bluish colour, typical of iron oxidation. The local temperature must have been high.

The second part corresponds to the range of high sliding velocities (low incidence angles), where the impulse ratio slowly decreases with the increase of relative tangential velocity. In this region, called gross slip, sliding will continue until separation and Brach [12] considered that $P_{\mathrm{t}}=f P_{\mathrm{n}}$ and $\mu=f$, where $f$ is the Coulomb's friction coefficient. The process of relative continuous sliding of two solids in contact (kinetic friction) is a complex subject $[7,11,17]$. For simplification, we describe these phenomena using a constant coefficient, defined as the ratio of tangential to normal forces. The problem arises when we need to know how $f$ varies with the relative velocity, materials, surface condition, lubrication, temperature, etc. In our case, the friction coefficient slowly decreases with the increase of the sliding velocity. Since we know that high temperature diminishes the mechanical resistance of materials, so, after a certain sliding velocity, the effect of temperature can lead to the formation of superficial pellicles of weak mechanical resistance, responsible for the decrease verified in the friction coefficient (see Fig. 6). On the other hand, adhesion phenomena increase with the increase in temperature. The balance between the increase of the adhesive phenomena due to temperature increase and the decrease of the mechanical resistance of the material which is formed in the contact's interface, may be the cause of the impulse ratio observed for high sliding velocities, i.e., the adhesive phenomena and the thermal effects will be responsible for the variation in the value of the impulse ratio with relative tangential velocity. The variation is, however, qualitative, since there are many factors that influence the adhesion that occurs between two materials subjected to sliding friction. The relative humidity, for example, might be important in the use of ceramic materials, as was demonstrated by Takadoum [38] in some alumina/metal pairs.

Fig. 7 shows the evolution of the kinematic restitution coefficient with relative tangential velocity. We observed that the restitution coefficient increases with tangential velocity and becomes nearly constant when a critical tangential velocity is reached, i.e., when a fragile chip is ejected from the test specimens. In this last case, the restitution coefficient approaches one. Unexpected experimental restitution coefficient values greater than one were, however, obtained. In order to understand these results, some hypothesis have been drawn, like the combined effect of the eccentricity of impact (the normal nn to the tangent plane at the contact point did not cross the rotation axis of cylindrical tracks) and the rotational movement of the cylindrical tracks.

\section{Interpretation through theoretical models}

\subsection{Application of classic impact theory to the pendulum system used}

Fig. 8 shows the mechanical system used in the experiments. It is assumed that the centre of percussion is close

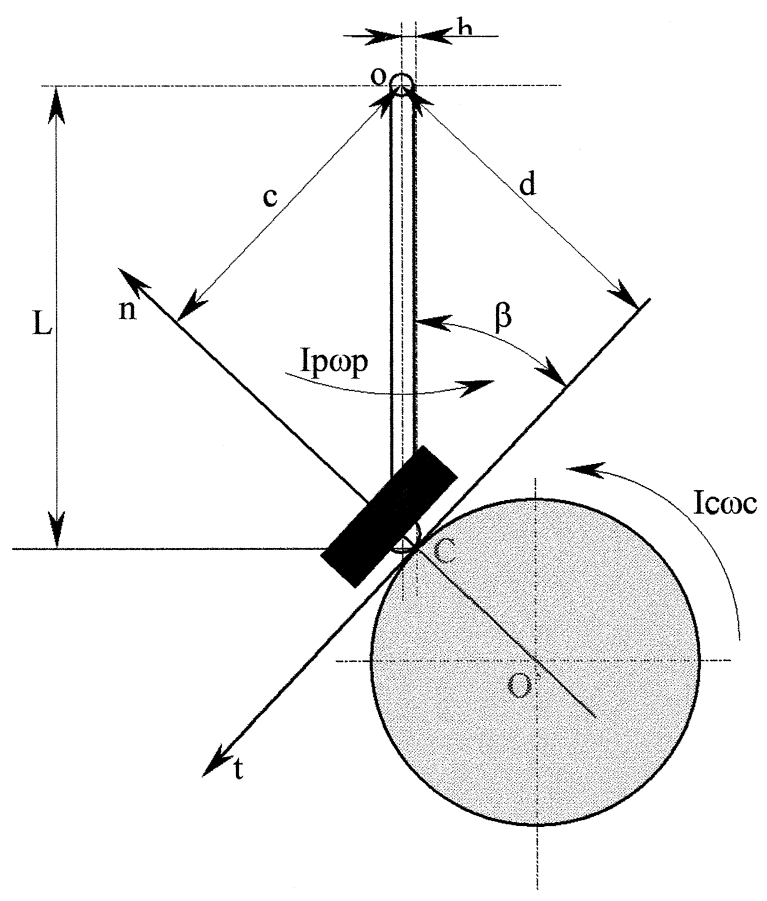

Fig. 8. Definition of impact system. 
to the impact point and, consequently, the reactive impulses are null on pendulum bearings. Using the impulse and momentum principles as well as the definition of kinematic coefficient of restitution $e$, it is possible to write:

$\left\{\begin{array}{l}\omega_{\mathrm{pf}}=-e \omega_{\mathrm{pi}} \\ \omega_{\mathrm{cf}}=\omega_{\mathrm{ci}}-\omega_{p i}(1+e) S \mu\end{array}\right.$

where $\mathrm{S}$ was defined by:

$S=\left(\frac{M R C}{I_{\mathrm{c}}}+\frac{R C}{L^{2}} \frac{I_{\mathrm{o}}}{I_{\mathrm{c}}}\right)$

In Eq. (6), $\omega_{\mathrm{pi}}, \omega_{\mathrm{ci}}, \omega_{\mathrm{pf}}$ and $\omega_{\mathrm{cf}}$ are the angular velocities of pendulum (p) and the rotating cylinder (c) before (i) and after (f) impact. $\mu$ is the impulse ratio (Eq. (1)), $e$ is the kinematic restitution coefficient, $L$ is the distance of the impact point to the pendulum rotation axis, $C$ is the distance between the normal $\mathrm{nn}$ on contact point and the pendulum rotation axis and $R$ is the radius of rotating cylinder (see Fig. 8). $I_{\mathrm{o}}$ and $I_{\mathrm{c}}$ are the moments of inertia of the pendulum and cylinder relative to the rotation axis, respectively. It should be noted that the off-set $h$ showed in Fig. 8 was disregarded. In addition, the restitution coefficient was defined considering the ratio between the normal component of the contact point velocity, after (f) and before (i) impact, i.e.:

$e=-\frac{v_{\mathrm{ncf}}}{v_{\mathrm{nci}}}$.

The coordinates of normal and tangential contact point velocities relatively to the $(n, t)$ referential, were defined as follows:

$\left\{\begin{array}{l}v_{\mathrm{nc}}=-C \omega_{\mathrm{p}} \\ v_{\mathrm{tc}}=R \omega_{\mathrm{c}}-D \omega_{\mathrm{p}} .\end{array}\right.$

If sliding stops during contact $\left(v_{\text {tcf }}=0\right)$, according to the impact theory of Brach [12], a critical impulse ratio can be defined by:

$\mu_{\mathrm{c}}=\frac{R \omega_{\mathrm{ci}}}{C \omega_{\mathrm{pi}}(1+e)\left(\frac{R S}{C}+\frac{e}{1+e}\right)}$.

Using the principle of conservation of energy:

$E_{\mathrm{i}}-E_{\mathrm{f}}=E_{\text {loss }}$

where $E_{\mathrm{i}}$ and $E_{\mathrm{f}}$ are the energy of the system before and after impact, respectively, and $E_{\text {loss }}$ is the energy lost on impact, it is possible to show that the energy loss is given by:

$$
\begin{aligned}
E_{\mathrm{loss}}= & \frac{1}{2} I_{\mathrm{o}} \omega_{\mathrm{pi}}^{2}\left[\left(1-e^{2}\right)+2 \frac{\omega_{\mathrm{ci}}}{\omega_{\mathrm{pi}}}(1+e) \frac{I_{\mathrm{c}}}{I_{\mathrm{o}}} S \mu\right. \\
& \left.-(1+e)^{2} \frac{I_{\mathrm{c}}}{I_{\mathrm{o}}} S^{2} \mu^{2}\right] .
\end{aligned}
$$

Taking the first and second derivatives relative to $\mu$, it can be seen that there is a $\mu$ that maximize the energy loss and it can be written as follows:

$\mu_{\max }=\frac{\omega_{\mathrm{ci}}}{\omega_{\mathrm{pi}}(1+e) S}$.

For our impact system, $\mu_{\mathrm{c}}=\mu_{\max }$ when $e=0$ only. The highest difference between these two values is obtained when $e=1$. For comparison purposes with experimental results, we defined an impact angle given by:

$\theta=\arctan \frac{\left|v_{\mathrm{nci}}\right|}{\left|v_{\mathrm{tci}}\right|}=\frac{\left|C \omega_{\mathrm{pi}}\right|}{\left|R \omega_{\mathrm{ci}}-D \omega_{\mathrm{pi}}\right|}$.

\subsection{Comparison between experimental results and theoret- ical models}

Using the definition of impact angle given above, we shall now compare the experimental results with the impact models of Stronge [8] and Brach [12]. Fig. 9 shows the variation of the impulse ratio with the impact angle. Fig. 9 also shows the limiting value of the impulse ratio proposed by Brach [12]. This limiting value was calculated with Eqs. (10) and (3) considering the case of a rigid spherical body $(\lambda=5 / 2)$ and a point mass $(\lambda=0)$. The measured impulse ratio is always below the curves corresponding to the critical impulse ratio for the case of pendulum system used (Eq. (10)) and the case of point mass impact (Eq. (3) with $\lambda=0$ ). Our experiments seem to confirm that, for high impact angles, there is a limiting value for impulse ratio.

The lumped parameter impact model of Stronge [8] looks at three ranges of impact angles. High impact angles, when $v_{\mathrm{t}} / v_{\mathrm{n}}<\mu \zeta^{2}$, where $v_{\mathrm{t}}$ and $v_{\mathrm{n}}$ are the tangential and normal initial components of impact velocity, $\mu$ is the Coulomb's friction coefficient (dynamic friction) and $\zeta^{2}$

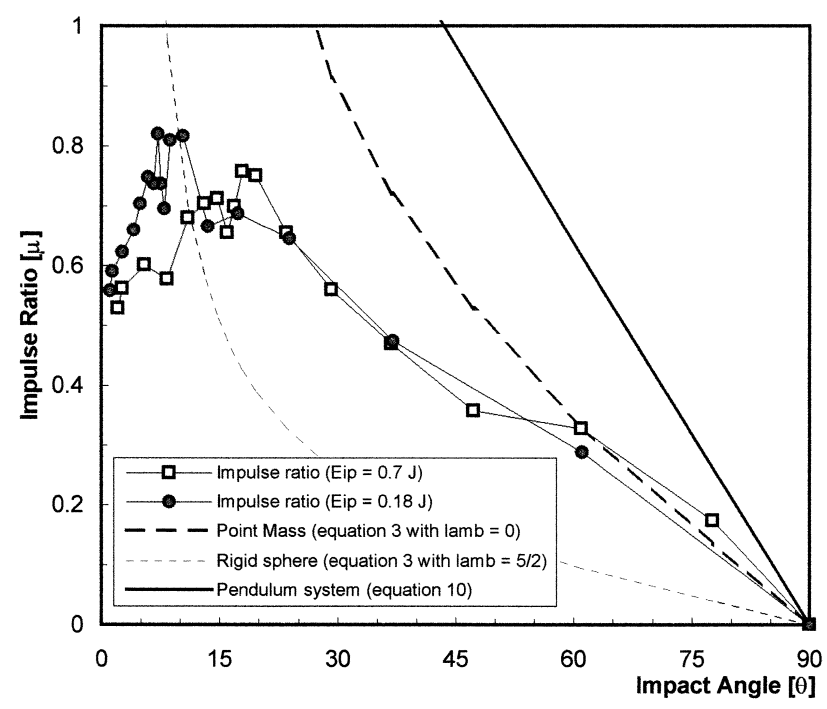

Fig. 9. Impulse ratio $\mu$ vs. impact angle $\theta$. 
is the ratio of normal to tangential stiffness at the contact point $[8,17]$. In this region, stick begins on first contact and continues until a time $t$ when slip begins. Slip continues until separation. High and medium impact angles, when $\mu \zeta^{2}<v_{\mathrm{t}} / v_{\mathrm{n}}<m(1+e) m_{\mathrm{n}} / m_{\mathrm{t}}$, where $m_{\mathrm{n}}$ and $m_{\mathrm{t}}$ are the tangential and normal components of the inverse of mass matrix. Initially, there is sliding at the contact point. After this period there may be alternate periods of stick and slip phenomena. With small angles of incidence, when $v_{\mathrm{t}} / v_{\mathrm{n}}>$ $\mu(1+e) m_{\mathrm{n}} / m_{\mathrm{t}}$, the slip continues in the initial direction throughout the entire contact period. This contact process is termed gross slip [8].

Some authors $[7,8]$ report that the wear rate due to repeated impacts at oblique angles of incidence can be related to the maximum tangential force and that this force varies with impact angle. In the model of Stronge [8], the tangential force $T(t)$ can be calculated as a function of the impact angle $\theta$. In this model, the maximum value of friction occurs during the compression period if the ratio of tangential to normal frequencies $\omega / \Omega \geq 1$ and the maximum tangential force is independent of the restitution coefficient (energetic coefficient). In Ref. [8], Stronge formulated equations that allow the calculation of the maximum tangential and normal forces for the three ranges of impact angles mentioned above. In Fig. 10, we compare our experimental non-dimensional data with the model of Stronge [8]. In our calculations, we consider the contact between a solid sphere, composed of material with Poisson's ratio $\nu=0.22$, and a target with Poisson's ratio $\nu=0.3$. For this case, the ratio of normal to tangential stiffness is $\zeta^{2}=1.18$, the mass ratio $m_{\mathrm{n}} / m_{\mathrm{t}}=7 / 2$ and the ratio of tangential to normal frequencies is $\omega / \Omega=$ 1.72. Furthermore, the experimental points in Fig. 10 have been obtained taking a constant time of compression of 0.9 and $1 \mathrm{~ms}$, corresponding to pendulum kinetic impact ener-

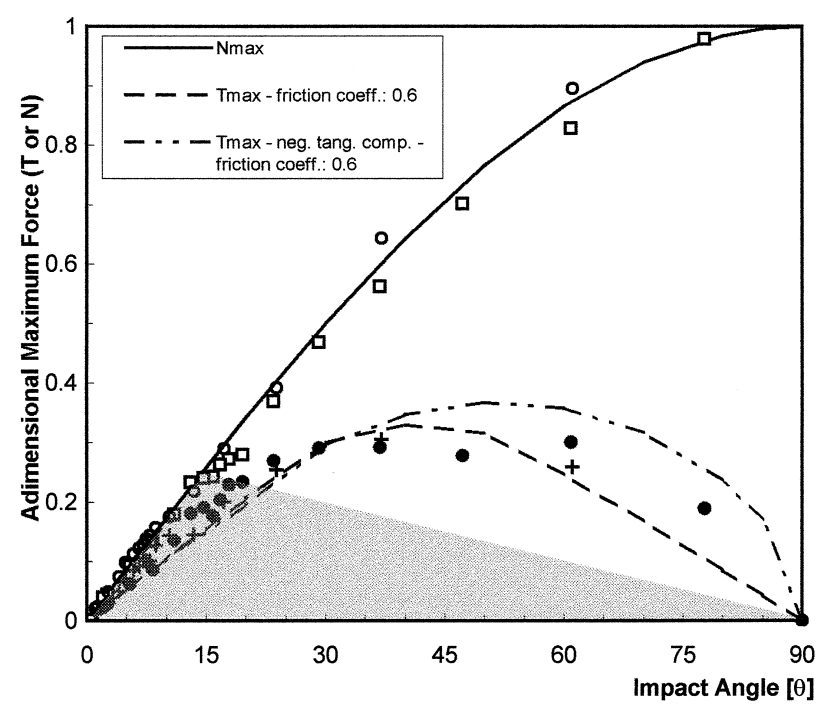

Fig. 10. Maximum normal and tangential force vs. impact angle according to the model of Stronge [8]. The grey zone corresponds to the beginning of 'gross' slip.

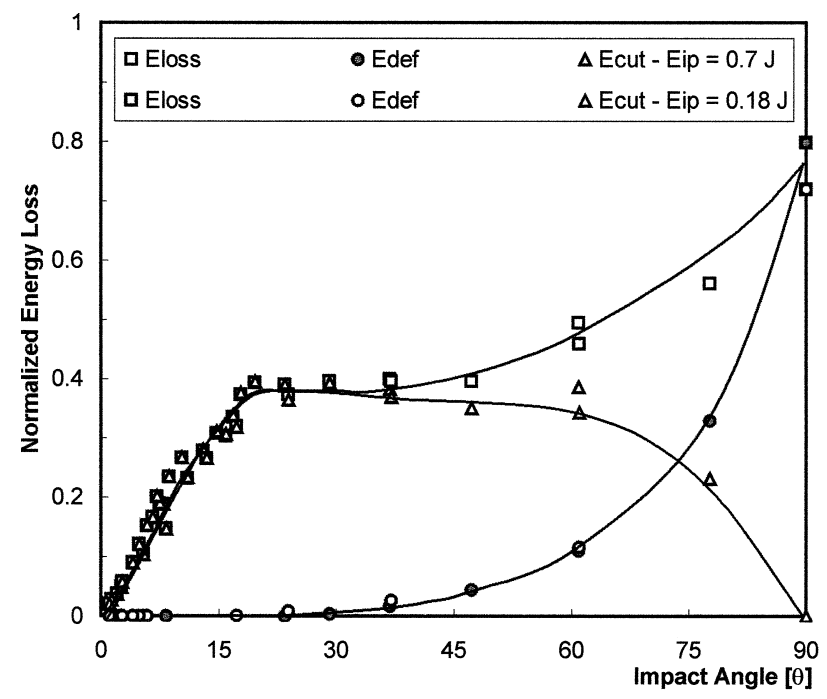

Fig. 11. Normalized impact energy loss vs. impact angle according to the impact model of Brach [12].

gies of 0.7 and $0.18 \mathrm{~J}$, respectively. We concluded that the model predicts the maximum impact forces generated on impact very well. Using this model, we see that the critical value of tangential velocity which allows chip ejection is close to the value required for the beginning of sliding throughout the impact duration. In Fig. 10, we draw the predicted curves of non-dimensional frictional force corresponding to a mean dynamic friction coefficient of 0.6, obtained in our experiments (see Fig. 6). According to Stronge [8], for oblique impact, tangential compliance reduces the largest friction force in comparison with friction generated if the contact region has negligible tangential compliance. If tangential compliance is negligible, oblique impact always results in an initial period of sliding. This sliding stops before separation and there is a final period of stick, unless the impact angle is low enough to cause gross slip.

The model of Brach [12] also allows the study of the loss of kinetic impact energy. In Fig. 11 we can see the variation of normalized energy loss during contact with the impact angle, calculated with a non-dimensional form of Eq. (12) given by $E^{*}=E_{\text {loss }} / E_{\mathrm{i}}$ (see Section 5.1). It can again be seen that the maximum energy loss due to tangential effects has a maximum value when there is chip ejection. This figure also shows a characteristic typical of processes where deformation wear is predominant. It is frequently seen on spherical solid particle erosion $[18,29]$.

\section{Conclusions}

The pendulum test machine used here is an important experimental means for modelling the behaviour of materials subjected to single particle impact. We can relate the normal and tangential impulses with the superficial damage to the materials. 
The tribological behaviour on impact between hard $\alpha$-alumina spheres and a ductile low alloy steel (AFNOR 25CD4) was studied. On normal impact, the kinetic energies used in the experiments produce a small indentation without lip formation (elastic-plastic impact). In the experiments where there is a finite relative tangential velocity between the two bodies there is always lip formation. The indentations show lateral and frontal lips. When a critical relative tangential velocity is reached, an ejection of a small fragile oxidized chip of the target material is observed. We found that the duration of contact and impulse ratio reaches a maximum value. At high sliding velocities the chip always sticks to the surface of projectiles.

The tangential impulses can be decomposed in two distinct parts. One for low relative tangential velocities (high impact angles), where the duration of contact and the impulse ratio rapidly increase with the tangential velocity. Another, for high sliding speeds (low impact angles), where the duration of contact and the impulse ratio slowly decrease with tangential velocity. The critical sliding velocity can be related to a critical attack angle common in solid particle erosion processes. This critical angle slightly increases with the increase of the impact velocity. It may be due to the slight increase of strain ratio, corresponding to the range of the kinetic impact energies used in our tests. However, this must be confirmed for a large range of normal impact velocities.

The classic impact theory of Brach [12] and the lumped parameter impact model of Stronge [8] were used and compared with experimental results. The experimental results seem to confirm the existence of a critical value of the impulse ratio as suggested by the impact theory of Brach [12]. It seems, moreover, to be related to the observed critical attack angle. For this angle, a maximum value of the kinetic energy loss due to the tangential effects was observed. Using the experimental values of compression time and dynamic friction coefficient, the model of Stronge [8] accurately predicts the values of the measured maximum normal and tangential forces generated in our impact tests.

\section{References}

[1] J.P. Nobre, A.M. Dias, R. Gras, Wear 211 (1997) 226-236.

[2] Y. Tirupataiah, G. Sundararajan, J. Mech. Phys. Solids 39 (2) (1991) 243-271.

[3] D. Tabor, Proc. R. Soc. London, Ser. A 192 (1948) 247-274.

[4] A. Seireg, E.J. Weiter, Wear 8 (1965) 208-219.

[5] N. Maw, J.R. Barber, J.N. Fawcett, Wear 38 (1976) 101-114.

[6] W.J. Stronge, Proc. R. Soc. London, Ser. A 431 (1990) 169-181.

[7] R.M. Brach, Int. J. Impact Eng. 13 (1) (1993) 21-33.

[8] W.J. Stronge, Int. J. Impact Eng. 15 (4) (1994) 435-450.
[9] G. Sundararajan, Int. J. Impact Eng. 9 (3) (1990) 343-358.

[10] S.B. Ratner, E.E. Styller, Wear 73 (1981) 213-234.

[11] I.V. Kragelsky, Friction and Wear-Calculation Methods, Pergamon, Oxford, 1982.

[12] R.M. Brach, Int. J. Impact Eng. 7 (1) (1988) 37-53.

[13] I. Finnie, Wear 3 (1960) 87-103.

[14] J.G.A. Bitter, Wear 6 (1963) 5-21, Part I.

[15] J.G.A. Bitter, Wear 6 (1963) 169-190, Part II.

[16] I. Kleis, H. Kangur, in: J.E. Field, J.P. Dear (Eds.), Proc. 7th Int. Conf. on Erosion by Liquid and Solid Impact, Cambridge, 1987, pp. $45 / 1-45 / 5$.

[17] K.L. Johnson, Contact Mechanics, Cambridge Univ. Press, 1985.

[18] I.M. Hutchings, R.E. Winter, J.E. Field, Proc. R. Soc. London, Ser. A 348 (1976) 379-392.

[19] I.M. Hutchings, D.G. Rickerby, N.H. Macmillan, Int. J. Mech. Sci. 23 (1981) 639-649.

[20] D.G. Rickerby, N.H. Macmillan, Int. J. Mech. Sci. 22 (1980) 491-494.

[21] T.S. Sriram, T.H. Kosel, in: J.E. Field, J.P. Dear (Eds.), Proc. 7th Int. Conf. on Erosion by Liquid and Solid Impact, Cambridge, 1987, pp. $67 / 1-67 / 8$.

[22] G. Sundararajan, Wear 140 (1990) 369-381.

[23] J.H. Neilson, A. Gilchrist, Wear 11 (1968) 111-121.

[24] I. Finnie, Wear 19 (1972) 81-90.

[25] I.M. Hutchings, Proc. 5th Int. Conf. on Erosion by Liquid and Solid Impact, Cambridge, 1982, pp. 27/1-27/9.

[26] G. Sundararajan, P.G. Shewmon, Wear 84 (1983) 237-258.

[27] G. Sundararajan, Wear 84 (1983) 217-235.

[28] L.K. Ives, A.W. Ruff, Wear 46 (1978) 149-162.

[29] I.M. Hutchings, R.E. Winter, Wear 27 (1974) 121-128.

[30] G. Sundararajan, Wear 149 (1991) 129-153.

[31] E. Rabinowicz, Proc. 5th Int. Conf. on Erosion by Liquid and Solid Impact, Cambridge, 1982, pp. 38/1-38/5.

[32] A.J. Sedriks, T.O. Mulhearn, Wear 6 (1963) 457-466.

[33] G. Huard, M. Fiset, Wear 98 (1984) 27-44.

[34] J.M. Challen, P.L.B. Oxley, E.D. Doyle, Wear 88 (1983) 1-12.

[35] J. Blouet, J. Seige, R. Gras, R. Courtel, Annals of CIRP 12 (1) (1976) 251-255.

[36] J. Seige, Int. Rep. Laboratoire de Tribologie, ISMCM, France, 1976.

[37] A.D. Lewis, R.J. Rogers, J. Sound Vibration 125 (3) (1988) 403-412.

[38] J. Takadoum, Wear 170 (1993) 285-290.

J.P. Nobre is a research assistant of the Mechanical Engineering Department, University of Coimbra. He is currently a $\mathrm{PhD}$ student at the same department. He received his Masters in Mechanical Engineering Science at the University of Coimbra, in 1996, for his studies on contact mechanics.

Professor A.M. Dias obtained his degree of Docteur ès-Sciences Physiques at the University of Paris XI, in 1985, in the field of the materials engineering. At the moment he is an Associate Professor of the Mechanical Engineering Department, University of Coimbra and his field of research is the mechanical behaviour of materials and surfaces engineering.

Professor R. Gras obtained his degree of Docteur ès-Sciences Physiques at the University of Paris VI, in 1989. He is a Professor at the ISMCMCESTI-Institut Supérieur des Matériaux et de la Construction Mécanique, Saint-Ouen, Paris and the director of the Tribology Group at the LISMMA (Laboratoire d'Ingenierie des Structures Mécaniques et des Matériaux). 